mechanism is thought to be due to deformation of the skull with fracture and immediate expulsion of CSF, closely followed by recoil and suction of air into the cranium. The presence of free air itself rarely causes significant morbidity, although the concept of "tension pneumocephalus" is well documented and can result in herniation syndromes if not recognised and decompressed. Other findings include headache, paresis, CSF rhinorrhoea or otorrhoea, seizures, frontal lobe dysfunction, and the patient's awareness of a succussion splash. ${ }^{3}$
Computed tomography is now the modality of choice for accurate description of the size and extent of intracranial air, although standard $x$ ray imaging will demonstrate most significant aerocoeles. This unusual case provided an opportunity for the diagnosis to be made in the resuscitation room.

1 Chiari H. Ueber Einen Fall von Luftansammlung in der Ventrikien des Mensclichen gehirom. $Z$ Heilk Prag 1884;5:383-90.

2 Briggs M. Traumatic pneumocephalus. Br $\mathcal{F}$ Surg 1974;61: $307-12$.

3 Orebaugh SL, Margolis JH. Post-traumatic intracerebral pneumatocele: case report. $\mathcal{F}$ Trauma 1990;30:1577-80.

\title{
Posterior dislocation of sternoclavicular joint in a child
}

\author{
S R Abdulla, S G Gandham
}

A 12 year old boy presented to the accident and emergency department after a fall off his bike. $\mathrm{He}$ was complaining of severe pain over the right collarbone and inability to move the right shoulder.

He was given oral dihydrocodeine and was sent for a radiograph of the right shoulder. On examination he was still in pain and the vital signs were normal. There was no swelling, deformity, or tenderness over the right shoulder or the lateral part of the right clavicle but there was swelling and severe tenderness over the right sternoclavicular joint and movements at the shoulder were restricted and painful.

Department of

Accident and

Emergency Medicine, Glan Clwyd Hospital,

Rhyl, Denbighshire

LL18 5UJ

$S$ R Abdulla

S G Gandham

Correspondence to: Mr Abdulla, Specialist Registrar in Accident and Emergency.

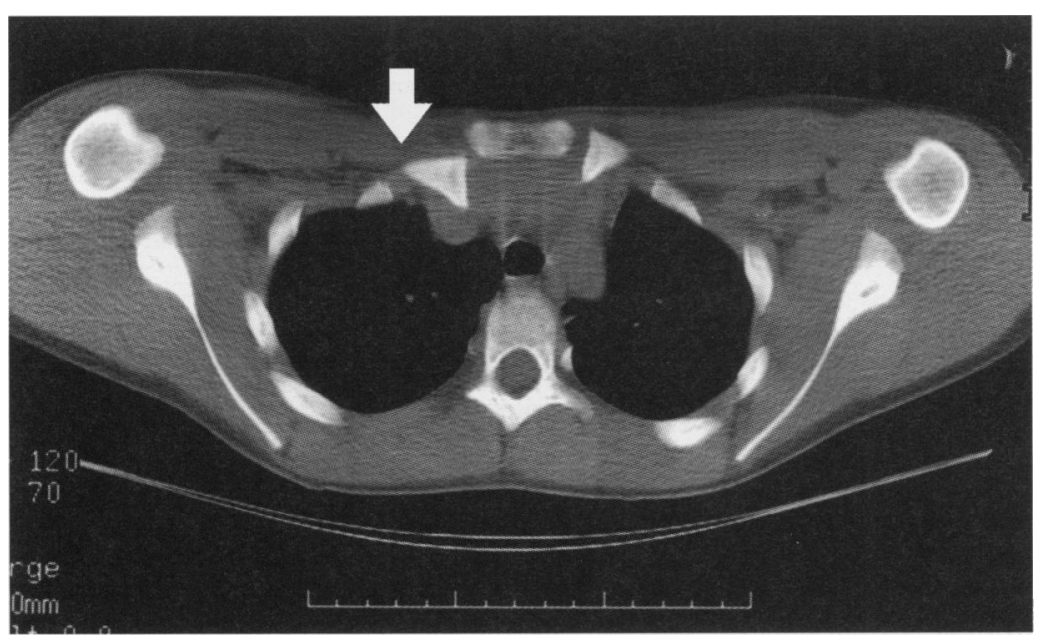

Posterior dislocation of the sternoclavicular joint is a rare injury and especially so in children. ${ }^{1}$ Its importance lies in the fact that it is difficult to pick up on plain radiographs and although certain oblique views of the sternoclavicular joint may give a good diagnostic yield, ${ }^{2}$ computed tomography is the best way of attaining a definite diagnosis. ${ }^{1}$ However the key to the diagnosis is a strong clinical suspicion that should arise from the nature of the injury, the localisation of signs and symptoms, and especially the absence of fracture on the plain radiograph.

Early diagnosis is the key to successful management because the aim is to achieve a closed reduction, which is much safer than open reduction, and involves applying lateral traction to abducted arm under a general anaesthetic. ${ }^{3}$ An alternative method is to grasp the medial end of the clavicle with a sterile towel clips and apply a forward traction. The reduction is maintained by a figure of eight bandage, which should be kept for at least four to six weeks. ${ }^{3}$

An important aspect in the management is that once diagnosed the patient should be treated as a major resuscitation candidate because of the serious and sometimes potentially life threatening complications that may ensue before and especially after reduction. ${ }^{3}$ Possible complications are trauma to the trachea; pneumothorax; laceration or compression of the superior vena cava, the subclavian artery, and the carotid artery; injury to the brachial plexus; and oesophageal trauma.

1 Yang J, Al-Etani H, Letts $M$. Diagnosis and treatment of posterior sternoclavicular joint dislocations in children. $\mathrm{Am}$ f Orthop 1996;25:565-9.

2 Cope R, Riddervold HO. Posterior dislocation of the sternoclavicular joint: report of two cases, with emphasis on 1988;17:247-50.

3 Pearson MR, Leonard RB. Posterior sternoclavicular dislocation: a case report. $¥$ Emerg Med 1994;12:783-7. 